\title{
FMS におけるパートセレクション問題の一解法*
}

\author{
李 鉄 克*1, 中 村 信 人*2 $^{* 2}$
}

\section{A Solution Method for the Part Selection Problem in an FMS}

\author{
Tie-ke LI and Nobuto NAKAMURA
}

\begin{abstract}
In this paper we consider a critical production scheduling problem, the part selection problem, for the effective utilization of a flexible manufacturing system (FMS). The problem is to determine how to split up the production requirement given for a certain period into a number of subsets in order to minimize the number of tool changeovers and the sum of maximum workloads. First, we describe the part selection problem and show that, although the problem can be formulated as an integer programming problem, the number of integer variables is too large to obtain optimal solutions for realistic problems. Then, we develop a heuristic method and carry out the computational experiments to test its efficiency and validity. The computational results show that our heuristic method is efficient and can be used to solve large-scale problems.
\end{abstract}

Key Words: Flexible Manufacturing System, Part Selection, Heuristic Algorithm

\section{1. 緒}

FMS を構成する各機械は，一般に多様な加工機能 を持つが，機械の工具マガジン容量に制約があるため， 所要工具のすべてを同時に収納することができない。 したがって，ある生産期間(例えば 1 週間)に加工すべ きすべての部品を加工するには，何回かの工具段取り が必要となる，そのため，機械の工具マガジン容量の 制約下で, 工具段取回数ならびに最大ワークロードの 和を最小ならしめるように，おのおのの工具段取りで 加工すべき部品を選択するパートセレクション問題が 生じる、この問題は各機械での作業順序を決めるいわ ゆるシーケンシングの前に解決されなければならない 重要な問題である.FMS を効率的に運用するには，パ ートセレクション問題に対する有効的な解法が不可欠 である。

機械の工具マガジンの容量制約を考慮した FMSの 生産計画問題は一般に整数計画問題としての定式化が 可能であり (1) (3)，本研究で考慮するパートセレクショ ン問題においても，整数計画問題として定式化するこ

\footnotetext{
* 平成元年 3 月 9 日 中国四国支部第 27 期絰会演演会におい て善演, 原稿受付 平成元年 5 月 31 日.

*1 准员, 広岛大学大学院（⿶724 東広岛市西条下見）。

*2 正員, 広島大学工学部.
}

とによってその最適解を求めることができる。しかし， その方法はかなり小規模の問題しか解くことができな いため，現実の大規模な問題には応用できない，そこ で, 本研究では現実の大規模なパートセレクション問 題を取扱うことができるヒューリスティックな一解法 を提案する。

$$
\text { 2. パートセレクション问題 }
$$

\section{$2 \cdot 1$ 欺号の説明と前提条件}

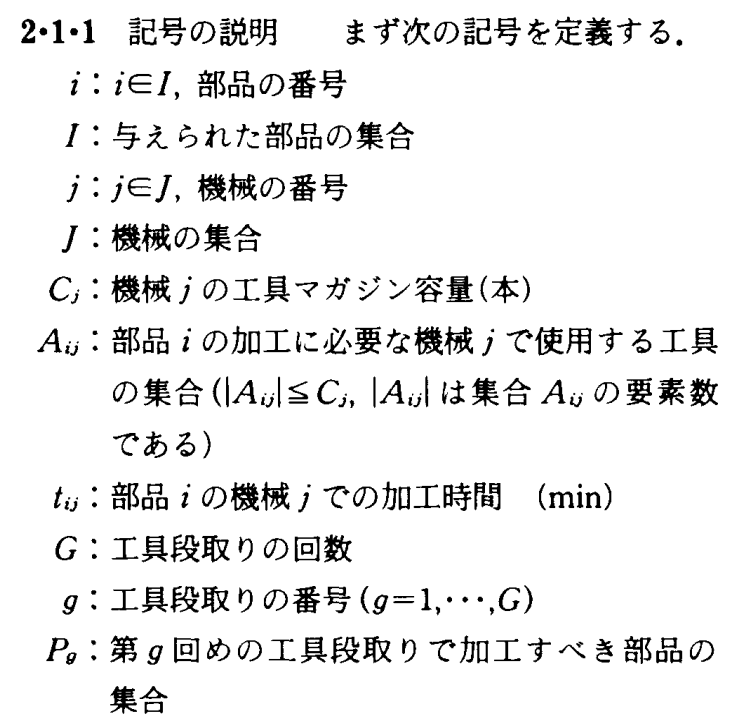


$T_{j g}$ : 第 $g$ 回めの工具段取りで加工すべき部品の 機械 $j$ でのワークロード $\sum_{i \in p g} t_{i j}$

$2 \cdot 1 \cdot 2$ 前提条件 本研究の前提条件は次のもの である。

（1）ある生産期間(例えば 1 週間)において，加工 すべき部品と各部品の各機械での加工時間および使用 工具は決められている。

（2）加工すべき部品のすべてを加工するのに必要 な工具を同時に機械工具マガジンに収納することがで きず，工具段取りが必要となる。

（3）各機械の工具マガジンにおける工具の交換は 前回の工具段取りで加工すべき部品が全部完成された 時点で同時かつ一斉に行われる.

\section{$2 \cdot 2$ 制約条件と目的战数}

$2 \cdot 2 \cdot 1$ 制約条件 ある解 $\left(P_{1}, P_{2}, \cdots, P_{G}\right)$ がパー トセレクション問題の実行可能解であるための条件は 以下のとおりである.

（1）各工具段取りにおいて，同時に各機械の工具 マガジンに配置すべき工具の数がその工具マガジンの 容量を超えない.すなわち

$$
\left|\bigcup_{i \in p g} A_{i j}\right| \leqq C_{j} \quad \forall j \in J, g=1, \cdots, G
$$

（2）与えられた部品はすべて加工されなければな らない.すなわち

$$
\cup_{g=1}^{G} P_{g}=I \cdots
$$

$2 \cdot 2 \cdot 2$ 目的関数 FMSのパートセレクション 問題においては工具段取り回数の最小化と最大ワーク ロードの和の最小化の二つの目的関数が考えられ $ろ^{(2)(4)}$. 前者が工具段取りにかかわる非加工時間の最 小化を狙ったものであり，後者が同時かつ一斉の工具 交換(前提条件 (3))によるシステムの稼動率を低下さ せるという問題点の軽減を狙ったものである．本研究 では，工具段取り回数の最小化を第 1 目的関数, 最大 ワークロードの和の最小化を第 2 目的関数として取扱 い, 目的関数 2 を目的関数 1 に従属させる. 式で表せ ば次のようになる。

目的関数 1 Minimize $G$

目的関数 2 Minimize $T=\sum_{g=1}^{G}\left(\max _{j \in j}\left\{T_{j g}\right\}\right)$

\section{$2 \cdot 3$ 最適解を求めるためのアプローチとその計算} 経験 以上で定義したFMSのパートセレクション 問題は組合せ問題としての性質を持つ問題である。そ こで，本研究の第 1 歩として，まず整数計画法に基づ く最適解を求める方法を開発した(付録 1 を参照のこ と).この方法の実用性を調べるために，まず表 1 に示 すような 8 部品, 2 機械, 12 工具の簡単な問題を設定
した.この問題に対して， $G=3$ のときの整数変数の数 は 63 個であり，混合整数計画プログラム（MIP）を利 用して，最適解 $(P=\{1,3\}, P=\{2,6\} ， P=\{4,5,7,8\}$, $G=3, T=175)$ を求めるのに $51 \mathrm{~s}$ の CPU 時間がか かった。さらに, 使用工具の数を 80 本 $\left(C_{1}=C_{2}=20\right.$ 本)に増やすと $G=3$ のときの整数変数が 267 個にな り，結局整数解さえも得られなかった。

以上のことから，明らかに，実際の部品数が数十， 工具数が数百以上の問題に対して, 整数計画法により 最適解を求めることは現実的でないことがわかる。し たがって, 実用的にはより良い近似解を求める七ュー リスティック解法が必要とされる．以下においてパー トセレクション問題に対する一つのヒューリスティッ ク解法を提案するのは以上の理由によるものである.

\section{3. ヒューリスティック解法}

$3 \cdot 1$ 解法の概要 本研究におけるパートセレク ション問題の第 1 目的関数と第 2 目的関数に対応し て,ここで提案するヒューリスティック解法は二つの フェーズから構成される。解法の第 1 フェーズでは, 目的関数 1 の值を最小化するように一つの初期解を生 成する，その際，各段取りでできるだけ多くの部品を 加工寸るように最初の工具段取りから各段取りで加工 すべき部品を順次選択し，一つの実行可能解を生成す る. 部品数が一定の場合, 各段取りでできるだけ多く の部品を加工することは段取り回数を隇少させること と等価となるため, 以上の選択手続きは目的関数 1 の 最小化に有効と考えられる。さらに，解法の第 2 フ ーズでは，目的関数 2 の值を隇少させることを目指し て, 解法の第 1 フェーズで得られた初期解における調 整を行う。この調整手続きは目的関数 1 の值を增加し

\begin{tabular}{|c|c|c|c|c|}
\hline \multirow[t]{2}{*}{$\begin{array}{l}\text { Part } \\
\text { (i) }\end{array}$} & \multicolumn{2}{|c|}{$\begin{array}{c}\text { Tool required } \\
\left(A_{i} .\right)\end{array}$} & \multicolumn{2}{|c|}{$\begin{array}{c}\text { Processing time } \\
\left(t_{i} j\right)(\min .)\end{array}$} \\
\hline & $j=1$ & $j=2$ & $j=1$ & $j=2$ \\
\hline 1 & $|1.2 .4 .6|$ & $\{7,10\}$ & 10 & 20 \\
\hline 2 & $\{1,2\}$ & $\{8,9\}$ & 40 & 10 \\
\hline 3 & $\{4\}$ & 181 & 20 & 10 \\
\hline 4 & $|4.5 .6|$ & 110.111 & 20 & 45 \\
\hline 5 & $|3|$ & $\{9,12\}$ & 45 & 10 \\
\hline 6 & $\{2,3,5\}$ & $\{7,8,9\}$ & 10 & 40 \\
\hline 7 & $|3|$ & $\{9\}$ & 20 & 10 \\
\hline 8 & $\{5\}$ & $\{11,12\}$ & 10 & 30 \\
\hline Tool & magazine & pacily: & $c:=c \geq=4$ & \\
\hline
\end{tabular}

表 1 使用工具と加工時間 
ないように目的関数 2 の值を隇少させることを狙って いる.

$3 \cdot 2$ アルコリリスム まず第 $g$ 回めの段取りで加 エすべき部品を選択する過程において, さらに次の記 号を定義する.

$I_{g}:$ まだ選択されていない部品の集合.

$M_{j g}$ :すでに機械 $j$ の具マガジンに配置されている 工具の集合.

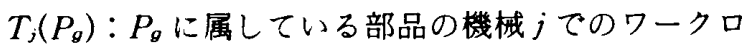
ード。これは次式で与えられる。

$T_{j}\left(P_{g}\right)=\sum_{i \in p_{g}} t_{i j}$

$T\left(P_{g}\right): P_{g}$ に対応している最大ワークロード。これは 次式で与えられる。

$$
T\left(P_{g}\right)=\max _{j \in J}\left\{T_{j}\left(P_{g}\right)\right\}
$$

$S_{g}$ : 選択可能な部品の集合.これは次式で与えられ る.

$$
S_{g}=\left\{i: i \in I_{g},\right.
$$

$$
\left.\left|A_{i j} \cup M_{j g}\right| \leqq C_{j} \forall j \in J\right\}
$$

これらの記号を用いることによって本研究で提案す るヒューリスティック解法は次のようなアルゴリズム の形で表現される。

[フェーズ 1：初期解を生成する]

手順 1 (パラメータの入力と初期值の設定)

(1) $A_{i j}, t_{i j}, C_{j}(i \in I, j \in J)$ を読み込む.

(2) $g \leftarrow 1, I_{1} \leftarrow I$, 手順 2 .

手順 2 (段取り $g$ における初期值の設定)

$$
P_{g} \leftarrow \phi, S_{g} \leftarrow I_{g}, M_{j g} \leftarrow \phi,
$$$$
T_{j}\left(P_{g}\right) \longleftarrow 0 \text {, 手順 } 3 \text { 个. }
$$

手順 3 (部品の選択と状態更新)

(1) $S_{\boldsymbol{g}}$ からの一つの部品 $i^{*}$ を選択する.

(2) $I_{g} \leftarrow I_{g}-\left\{i^{*}\right\}$ (“一”は集合の差の記号であ る), $P_{g} \leftarrow P_{g} \cup\left\{i^{*}\right\}, S_{g}, M_{j g}, T_{j}\left(P_{g}\right)$ を更新

して, 手順 4 へ。

手順 4 (段取り $g$ でこれ以上部品を加エすることがで きなくなるまでこの段取りで加工すべき部品 の選択の続行.)

$$
\begin{aligned}
& S_{g} \neq \phi \text { なら, 手順 } 3 \text { へ. } \\
& S_{g}=\phi \text { なら, 手順 } 5 \text { へ. }
\end{aligned}
$$

手順 5 (すべての部品が選択されるまで選択の続行)

$$
\begin{aligned}
I_{g} \neq \phi \text { なら }, & g \leftarrow g+1, I_{g} \leftarrow I_{\theta-1} \\
& \text { 手順 } 2 \text { へ. } \\
I_{g}=\phi \text { なら, } & \text { 手順 } 6 \text { へ. }
\end{aligned}
$$

[フェーズ 2 ：初期解を調整する]

手順 6 (調整可能かどうかの判断)

次の条件 $\mathrm{a} \sim \mathrm{c}$ を満たす変数の組 $(i, g[1]$, $g[2])$ があるかどうかを調べる。

a. $i \in P_{g(1)}$

b. $\left|A_{i j} \cup M_{j g[2]}\right| \leqq C_{j} \forall j \in J$

c. $\Delta(i, g[1], g[2])=$

$$
\left[T\left(P_{g(1]}-\{i\}\right)+T\left(P_{g[2]} \cup\{i\}\right)\right]
$$$$
-\left[T\left(P_{g[1]}\right)+T\left(P_{g[2]}\right)\right]<0
$$

もしあれば, 手順 $7 へ$,なければ手順 8

へ.

\section{手順 7 (調整と状態の更新)}

(1)手順 6 の条件を満たす変数の組の中から $\Delta(i, g[1], g[2])$ の值の最も小さいものを $\left(i^{*}, g[1]^{*}, g[2]^{*}\right)$ とする.

(2) $P_{g(1)} *_{\leftarrow} P_{g(1)} *-\left\{i^{*}\right\}$,

$P_{g[2]} * \leftarrow P_{g[2]} * \cup\left\{i^{*}\right\}$,

$M_{j g(1)}{ }^{*}, M_{j g(2)}{ }^{*}, T_{j}\left(P_{g(1)}\right)$,

$T_{j}\left(P_{\theta \mid 2]}\right)$ を更新して, 手順 6 へ.

手順 8 各段取りで加工すべき部品 $\left(P_{g}\right)$ および各機 械で使用する工具 $\left(M_{j g}\right)$ を出力して, 終了.

3•3 アルゴリズムの説明 まず,アルゴリズム のフェーズ 1 において目的関数 1 の最小化に重要なも のは手順 3 の部品 $i^{*}$ の選択方法である，本研究では, この手順において, 田中ら ${ }^{(5)}$ が NC 複合機械の場合に 対して提案した共通工具数と追加工具数の概念を FMSの場合に適用するために，それらを次のように 定義する。

（1）共通工具数 $\left(=\sum_{j \in J}\left|A_{i j} \cap M_{j g}\right|\right)$ :これは，も し部品 $i$ を選択した場合に, その加工に必要とする工 具とすでに各機械の工具マガジンに配置されている工 具との間の共通工具数である.

(2) 追加工具数 $\left(\sum_{j \in J}\left|A_{i j}-A_{i j} \cap M_{j g}\right|\right)$ :これは, もし部品 $i$ を選択した場合に，新たに各機械の工具マ ガジンに追加しなければならない工具数である.

以上の準備のもとに, 工具交換回数を隇少するため に，常に共通工具数が多くかつ追加工具数の少ない部 品を選択すべきという考えに基づいて，本研究では次 の選択ルール $(\mathrm{GR})$ を提案する.

GR :

$$
Q\left(i^{*}\right)=\max _{i \in s g} Q(i)
$$

により ${ }^{*}$ を求める。ただし，

$$
Q(i)=\frac{\sum_{j \in J}\left|A_{i j} \cap M_{j \ell}\right|}{\sum_{j \in J}\left|A_{i j}\right|}
$$

もし同值の場合, 使用工具数の最も大きいものを選 択する.

このルールは次のように解釈できる.

(1) $\sum_{j \in J}\left|A_{i j}-A_{i j} \cap M_{j g}\right|=0$ のとき, $Q(i)$ が最 大值 1 をとる。 すなわち, 追加工具数が零の部品があ 
る場合, GR ルールはこれらの部品を優先に選択する。

(2) $\sum_{j \in J}\left|A_{i j}-A_{i j} \cap M_{j g}\right|>0$ のとき, 次の関係が 成立する(証明略) : $\left(\sum_{j \in J} \mid A_{i j} \cap M_{j g}\right) /\left(\sum_{j \in J}\left|A_{i j}\right|\right) \sigma$ 值により部品を選択することは $\left(\sum_{j \in J} \mid A_{i j} \cap\right.$ $\left.M_{j g} \mid\right) /\left(\sum_{j \in J}\left|A_{i j}-A_{i j} \cap M_{j g}\right|\right)$ の值による部品を選択 することと等価である.すなわち, 追加工具数が零の 部品がない場合, GR ルールは共通工具数と追加工具 数との比の値の最も大きい部品を選択する.

そして，アルゴリズムのフェーズ 2 においては次の 三つの性質が考えられる。

性質 1 毎回の調整において目的関数 1 の值が増加し ない.

性質 2 毎回の調整において目的関数 2 の值が単調に 減少する。

性質 3 調整回数が収束する.

（性質 1 〜 3 の証明については付録 2 を参照のこと）

この三つの性質によって, アルゴリズムのフェーズ 2 において調整回数が有限であり，調整を行うごとに 解が改善されることが保証される。

さらに, 以上のヒューリスティック解法の求解プロ セスを例解によって明らかにするために, 表 1 に示す 問題に対してこのヒューリスティック解法を適用し た. その結果, 初期解の生成および調整過程は次のよ うになった。

初期解 : $\quad P_{1}=\{1,2,3\}$ (選択順序 : $1,2,3$ )

$P_{2}=\{5,6,7\}$ (選択順序 : $6,7,5$ )

$P_{3}=\{4,8\}$ (選択順序 : 4, 8)

$G=3, T=T_{1}+T_{2}+T_{3}$ $=70+75+75=220$

調整： (1) $P_{2}=\{5,6,7\} \rightarrow P_{2}=\{6,7\}$

$P_{3}=\{4,8\} \rightarrow P_{3}=\{4,5,8\}$

$T=220 \rightarrow T=205$

(2) $P_{1}=\{1,2,3\} \rightarrow P_{1}=\{1,3\}$

$P_{2}=\{6,7\} \rightarrow P_{2}=\{2,6,7\}$

$T=205 \rightarrow T=185$

(3) $P_{2}=\{2,6,7\} \rightarrow P_{2}=\{2,6\}$

$P_{3}=\{4,5,8\} \rightarrow P_{3}=\{4,5,7,8\}$

$T=185 \rightarrow T=175$

調整した解: $P_{1}=\{1,3\}, P_{2}=\{2,6\}, P_{3}=\{4,5,7,8\}$ $G=3, T=175$

調整した解は整数計画アプローチにより得られた最

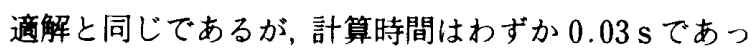
た.

\section{4. 数 值 部}

$4 \cdot 1$ 評価方法 本研究で提案したヒューリステ
イック解法の有効性を評価するには，その計算結果と 最適解との比較が望ましい。しかしながら，前述した ように最適解を求めることは現実規模の問題に対して 不可能であるため，ここでは次に示すような評価方法 によって本解法の有効性を検討する。

（1）目的関数 1 に関しては, 従来の部品選択ルー ルとの比較により本研究で提案した GR ルールの有効 性を検討する，比較用ルールとしては次の二つのもの を用いる。

（i ） 八ミング距離の最も小さい部品を選択する方

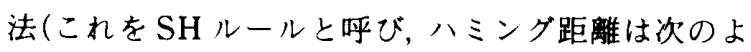
うに定義される: $H(i)=\Sigma_{j \in J}\left|A_{i j} \cup M_{j \theta}\right|$

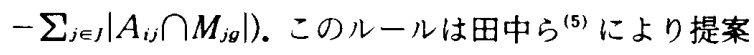
されたものである。彼らは使用工具の類似度に基づい たいくつかの部品選択方法の中でこのルールが最良な 効果を得たことを示した。

(ii) 使用工具数 $\left(\sum_{j \in J}\left|A_{i j}\right|\right)$ の最も大きい部品を 選択する方法(これを LTルールと呼ぶ)。これはよく 知られているビンパッキングルール FFDの応用であ る(このルールでは使用工具の類似度が考慮されな ৬).

（2）目的関数 2 に対しては，調整した解の初期解 に対する相対改善率 $I_{T}(\%) に よ り$ 調整手続きの効果 を評価する，そして下界値に対する相対誤差 $E_{T}[\%]$ によって、ヒューリスティック解法の効果を評価す る. $I_{T}[\%]$ と $E_{T}[\%]$ はそれぞれ次のように定義さ れる。

$$
I_{T}[\%]=\left[\left(T_{0}-T\right) / T_{0}\right] \times 100
$$

ただし， $T_{\theta}$ と $T$ はそれぞれ初期解と調整した解の目 的関数 2 の值である.

$$
E_{T}(\%]=[(T-\mathrm{LBT}) / \mathrm{LBT}] \times 100
$$

ただし，目的関数 2 の下界值 LBT は次式により計算 される。

$$
\mathrm{LBT}=\max _{j \in J}\left(\sum_{i \in t} t_{i j}\right)
$$

$4 \cdot 2$ 凧題の設定 FMSのパートセレクション 問題は工具マガジン容量に制約があるため生じたもの である、そのため, 以下のように工具マガジン制約が 厳しい場合 (問題 1 ), 中程度の場合(問題 2 ), 緩い場 合(問題 3 )の三つの問題を設定した。

問題 1 : 部品数 $=50$, 機械台数 $=4$, 工具マガジン 容量 $=20 \times 4$

問題 2 : 部品数と機械台数は問題 1 と同じである. 工具マガジン容量 $=30 \times 4$

問題 3 : 部品数と機械台数は問題 1 と同じである. 工具マガジン容量 $=40 \times 4$ 
問題 1〜3に対して部品選択ルール GR, SH, LT を用いて，各問題についてはおのおの 20 回の計算を 行った，その際，各機械の総負荷量がバランスされる ように配慮しながら各部品に対して，その加工に必要 とする機械台数が $2 \sim 4$, 各機械での加工時間が 10〜120, 各機械で使用する工具類が $1 \sim 10$ の一様分 布に従うものとして各值を設定した(結果として使用 工具の種類は平均 410 種となった).

4.3 計算結果 問題 1〜3に対する計算結果は 表 2 に示す.表 2 では $G$ は段取り回数(回), $T$ は最大 ワークロードの和 $(\mathrm{min})$ ，計算時間は調整した解にお ける平均計算時間である。

これらの計算結果から次のことがわかる.

（1）目的関数 1 に対しては, 当然のことながら使 用工具の類似度を考慮した部品選択ルールが有効であ る.その中には本研究で提案した GRルールが従来の 八ミング距離最小ルール SHよりも有効であること がわかる。そして，調整手続きは段取り回数の隇少に 対して効果があるが，それほど顥著ではなかった。

(2) 調整手続きは当然のことながら目的関数 2 の 值の減少に効果が大きい。すべての問題に対して, 調 整により目的関数 2 の值が $14 \%$ 以上減少した $\left(I_{T}(\%)\right.$ $\geqq 14 \%)$. 特に, 問題 1 を除くすべての場合については, 調整手続きにより下界值とかなり近い解 $\left(E_{T}[\%] \leqq\right.$ $10 \%)$ が得られた。本研究で提案したヒューリスティ ック解法は最大ワークロードの和の最小化を第 2 の目 的関数として取扱っているが, 工具マガジン容量が 1 作業に必要な工具数より十分大きい場合(問題 2,3 ), これに対しても効率的な解を得ることができた。

（3）設定した問題のパターンによって全体のパフ
オーマンスが大きく変わるが, 各ルールの相対的効果 および調整手続きの初期解に対する相対的効果は問題 のパターンによりあまり変化がないように思える(た だし、これには種々の問題パターンによるさらなる実 験が必要であろう)。

(4) 問題 1〜3のような中規模な問題に対して近 似解法の平均計算時間は $5 \mathrm{~s}$ 前後である。ささらに 100 部品, 6 機械, 1000 工具のような大規模な問題に対し ても実行したが，計算時間は $1 \mathrm{~min}$ 前後であった。こ れらの計算経験から，本研究で提案するヒューリステ イック解法は実用的な方法であり，大規模な問題に対 しても適用可能であることがわかる。なお，本研究に おけるすべての計算は HITAC M-680 H コンピュー タで行った。

\section{5. 結}

パートセレクション問題は FMS の運用上における 一つの重要な問題である.しかし、この問題は組合せ 問題としての性質を持つため，現実規模の問題に対し てその最適解を求めるのは非常に困難である。そのた め, 本研究ではパートセレクション問題における一つ のヒューリスティック解法を提案した。ささらに数值計 算の結果から本研究で提案した解法は有効であり，大 規模な問題にも応用できることがわかった。 今後の課 題としては，同時かつ一斎の工具交換の条件を緩和し た場合の解法及びパートセレクション問題とシーケン シング問題を統合したスケジューリングアプローチの 開発があげられる。

表 2 問題 $1 \sim 3$ の計算結果 (平均值)

\begin{tabular}{|c|c|c|c|c|c|c|c|c|c|}
\hline \multirow[t]{2}{*}{ Problem } & \multirow{2}{*}{$\begin{array}{c}\text { Selection } \\
\text { rule }\end{array}$} & \multicolumn{3}{|c|}{ Initial solution } & \multicolumn{2}{|c|}{ Adjusted } & \multicolumn{2}{|c|}{ solution } & \multirow{2}{*}{$\begin{array}{l}\mathrm{CPU} \\
\mathrm{tine}\end{array}$} \\
\hline & & G & $\mathrm{T}$ & E $1 \%$ & G & T & $1, \%$ & $E_{\top} \%$ & \\
\hline & GR & 11.90 & 3360.3 & $37.9 \%$ & 11.90 & 2829.1 & $15.4 \%$ & 16. $1 \%$ & 5.23 \\
\hline \multirow[t]{3}{*}{1} & SH & 12. 35 & 3353.7 & $37.6 \%$ & 12. 30 & 2813.6 & $16.0 \%$ & $15.4 \%$ & sec. \\
\hline & l. T & 13.05 & 3385.7 & $38.9 \%$ & 12. 95 & 2784.9 & $17.9 \%$ & 14. $3 \%$ & \\
\hline & GR & 7. 10 & 3204.4 & $31.5 \%$ & 7.05 & 2636.7 & $17.4 \%$ & $8.2 \%$ & 4. 76 \\
\hline \multirow[t]{2}{*}{2} & SH & 7. 35 & 3235.8 & $32.7 \%$ & 7. 35 & 2641.2 & $18.3 \%$ & $8.3 \%$ & sec. \\
\hline & LT & 7.85 & 3191.3 & $30.9 \%$ & 7.80 & 2631.1 & $17.6 \%$ & 7. $9 \%$ & \\
\hline \multirow{3}{*}{3} & $\mathrm{GR}$ & 4. 95 & 2990.5 & $22.7 \%$ & 4. 95 & 2550.4 & 14. $9 \%$ & 4. $6 \%$ & 4. 41 \\
\hline & $\mathrm{SH}$ & 5.20 & 3089.9 & $26.8 \%$ & 5.15 & 2563.6 & $16.7 \%$ & $5.2 \%$ & sec. \\
\hline & $1 . T$ & 5.55 & 3010.5 & $23.5 \%$ & 5.50 & 2533.1 & 15. $3 x$ & 3. $9 \%$ & \\
\hline
\end{tabular}

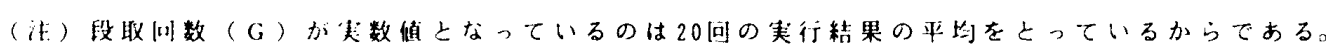




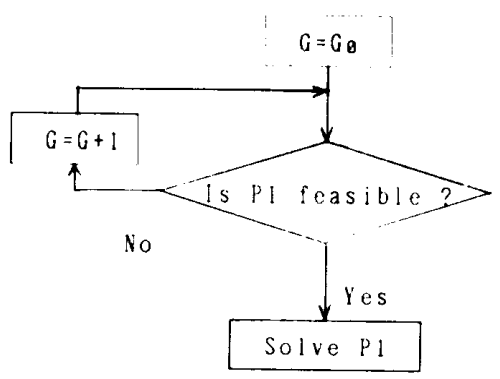

図 1 最適解を求めるアプローチ

(付録)

（1）最適解を求めるアプローチ

本研究で考慮したパートセレクション問題は図 1 に 示すような整数計画アプローチにより最適解を求める ことができる。

ここで，G $G_{0}$ は段取り回数の最小可能值である，P 1 は整数計画問題であり, 次のように定式化される. $[\mathrm{P} 1]$

$$
\text { Minimize } T=\sum_{g=1}^{C} T_{g}
$$

s.t.

$$
\begin{array}{ll}
\sum_{i \in I} t_{i j} x_{i g} \leqq T_{g} & \forall j, g \\
\left(\sum_{i \in I} b_{i r} x_{i g}\right) / N \leqq v_{r g} & \forall \gamma, g \\
\sum_{r \in R_{j}} v_{r g} \leqq C_{j} & \forall j, g \\
\sum_{g=1}^{G} x_{i g}=1 & \forall i \\
v_{r g}, x_{i g}, \in\{0,1\} ; T_{g} \geqq 0, & \text { 整数 ... }
\end{array}
$$

ここで $N$ : 部品数, $r:$ 工具番号, $R_{j}:$ 機械 $j て ゙$ 使 用する工具の集合.

$$
b_{i r}= \begin{cases}1 & r \in A_{i j} \\ 0 & \text { その他の場合 }\end{cases}
$$

决定変数

$$
x_{i g}= \begin{cases}1 & i \in P_{g} \text { の場合 } \\ 0 & \text { その他の場合 }\end{cases}
$$

$$
v_{r g}= \begin{cases}1 & \text { 第 } g \text { 回めの段取りで工具 } r \text { が必要な場 } \\ & \text { 合 } \\ 0 & \text { その他の場合 }\end{cases}
$$

他の記号は本文と同じである。

（2）性質 $1 \sim 3$ の証明

（i）性質 1 の証明 第 $k$ 回めの調整において， もし調整後, 段取り回数が增加すれば, 調整前 $P_{g[2]}{ }^{*}$ =фでなければならない。この場合,

$$
\begin{aligned}
T & \left(P_{g[1]}{ }^{*}\right)+T\left(P_{g[2]}{ }^{*}\right) \\
& =T\left(P_{g[1]}{ }^{*}\right) \\
& \leqq T\left(P_{g[1]}{ }^{*}-\left\{i^{*}\right\}\right)+T\left(\left\{i^{*}\right\}\right) \\
& =T\left(P_{g[1]}{ }^{*}-\left\{i^{*}\right\}\right)+\max _{j \in J}\left\{t_{i}{ }_{j}\right\} \\
& =T\left(P_{g[1]^{*}}{ }^{*}-\left\{i^{*}\right\}\right)+T\left(P_{g[2]}{ }^{*} \cup\left\{i^{*}\right\}\right)
\end{aligned}
$$

これは $\Delta\left(i^{*}, g[1]^{*}, g[2]^{*}\right)<0$ の条件(手順 6 の条件 c) と矛盾する.

（ii）性質 2 の証明第 $k$ 回めの調整において, 調整前後の目的関数 2 の值をそれぞれ $T^{k-1}, T^{k}$ とす ると,

$$
\begin{aligned}
& T^{k}=T^{k-1}-T\left(P_{g[1]}^{*}\right)-T\left(P_{g[2]}^{*}\right)+ \\
& T\left(P_{g[1]}^{*}-\left\{i^{*}\right\}\right)+T\left(P_{g[2]}{ }^{*} \cup\left\{i^{*}\right\}\right) \\
& =T^{k-1}+\Delta\left(i^{*}, g[1]^{*}, g[2]^{*}\right) \\
& <T^{k-1}
\end{aligned}
$$

（iii）性質 3 の証明現実の問題では, 目的関数 2 は有限的な最小值を持ち, 部品の加工時間は㒕散值 をとるため, 性質 2 により調整回数が有限であること がわかる。

\section{文献}

(1) Stecke, K. E.. Manage, Sci., 29- 3 (1983), 273.

(2) Hwang, S., in, Stecke, K. E. and Suri, S., R, Proc. 2nd ORSA/TIMS Conf. FMS, (1986), 297.

（3）李・畃村・新安，日本释営 [学会秋季大会子稿集，(1987） 108 .

(4) Van Looveren, A. J. ほか 2 名, in, Kusiak, A., ed., Modeling and design of FMS, (1986), 3.

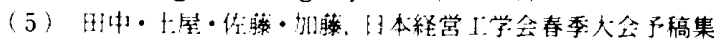
(1982), 129 